\title{
ЭКОНОМИЧЕСКАЯ ОЦЕНКА ИСПОЛЬЗОВАНИЯ ЭНЕРГОСБЕРЕГАЮЩИХ ТЕХНОЛОГИЙ В СФЕРЕ ЖИЛИЩНОГО ХОЗЯЙСТВА
}

\author{
(C) 2021 Иванкина Марина Степановна \\ кандидат экономических наук, \\ доцент кафедры экономики, организации и стратегии развития предприятия \\ Самарский государственный экономический университет, Россия, Самара \\ E-mail: msivankina@yandex.ru \\ (c) 2021 Соколов Алексей Александрович \\ студент \\ Самарский государственный экономический университет, Россия, Самара \\ E-mail: falcon1103@yandex.ru
}

В статье приводится экономическое обоснование применения технологий энергосбережения в сфере ЖКХ. Современные условия хозяйствования, нестабильность рынка, снижение производства энергоносителей и, как следствие, их удорожание заставляют применять новые технологические решения в таких традиционных сферах производства, как электроэнергетика. Ввиду того, что электроэнергетика неразрывно связывает выработку и потребление, минуя склад, вопрос учета является особенно актуальным. Вопросам энергосбережения и энергоэффективности уделяется большое внимание в современном мире. Решению проблем, связанных с экономным потреблением энергоресурсов, внедрением в производство энергосберегающих технологий, посвящены научные разработки отечественных авторов. Публикации Я.С. Фазлиевой и О. А. Ахмадеевой, Р. С. Цветова и В.Н. Мамеченкова и др. содержат ряд интересных предложений по внедрению методов и применению технологий, обеспечивающих эффективное использование энергоносителей в целом и электроэнергии, в частности. Объект исследования - потребители энергоресурсов. Предмет исследования - технологии энергосбережения. Теоретическое и методологическое значение исследования заключаются в обосновании целесообразности использования измерительной системы учета потребления электроэнергии в сфере ЖКХ. Практическое значение исследования заключается в экономической оценке результатов использования технологий энергосбережения.

Ключевые слова: технологии энергосбережения, потребление электроэнергии, учет потерь электроэнергии, энергоэффективность, экономический эффект.

В 2019 году существенно замедлилось мировое потребление электроэнергии: годовой прирост составил 0,7\% по сравнению со среднегодовыми темпами прироста за 2000-2018 гг., равными 3\%. Эксперты в качестве основных называют две причины: замедление темпов экономического роста и более умеренный климатический режим со средними, более высокими, чем обычно, температурами в ряде крупных стран мира. Исключение составляет лишь Китай (28\% от общемирового потребления электроэнергии), где потребление электроэнергии в 2019 году выросло на 4,5\%. Однако этот прирост намного ниже среднегодового прироста за два предшествующих десятилетия (10\% в 2000-2018 гг.) [8].

Резкое сокращение спроса на электроэнергию привело к снижению ее производства. Рост выработки электроэнергии в мире существенно замедлился и оказался намного ниже уровня прошлых лет: прирост в 2019 году составил 1\% против 3\% среднегодовых за 2000-2018 гг. [8].

Тенденция падения потребления и производства электроэнергии прослеживается в энергетической отрасли России: потребление электроэнергии в стране в 2020 году составило 1,05 трлн. кВт.ч, что на 2,3\% меньше, чем в предыдущем, а выработка электроэнергии сократилась на 3\%, составив 1,064 трлн. кВт•ч [5]. По мнению экспертов российской Ассоциации «НП Сообщество потребителей энергии», снижение потребления на цивилизованных энергетических рынках неизбежно приводит к падению цен. В России же цена на электроэнергию растет вне зависимости от того, увеличивается потребление или падает [9]. Доказательством этого может служить прогноз цен на энергоносители на 
2021 год для оптовых потребителей: в 2021 году потребление электроэнергии в первой ценовой зоне (европейская часть России и Урал) будет в среднем на 1,7\% ниже показателя 2019 года, а во второй ценовой зоне (Сибирь) восстановится до уровня 2019 года. При этом стоимость электроэнергии в 2021 году в европейской части России и на Урале может увеличиться на 5,9\% (до 1,25 тыс. руб. за 1 МВт.ч), а в Сибири - на 9,4\%, что соответствует 944 руб. за $1 \mathrm{MBт} \cdot ч$ [5].

Рост цен на электроэнергию для оптовых потребителей неуклонно повлечет увеличение тарифов на энергоносители для промышленных предприятий, а также компаний, функционирующих в сфере ЖКХ, что, в конечном итоге, скажется на повышении тарифов для населения. K тому же на уровень затрат населения на потребляемую электроэнергию сказывается ситуация, связанная с пандемией COVID-19: увеличение потребления электроэнергии населением в связи с переходом некоторых категорий населения на дистанционный режим работы и учебы. Проблема энергосбережения, актуальная всегда, сегодня стоит как никогда остро.

Проблемы учета потребления электроэнергии отражены в стратегии развития энергетики РФ. Одно из основных направлений энергетической стратегии России - обеспечение способности сферы экономики эффективно использовать энергоресурсы, предотвращать нерациональные затраты на внутреннее энергообеспечение и дефицит топливно-энергетических балансов на федеральном, региональном и муниципальном уровнях [4].

Эффективному, рациональному использованию электроэнергии способствует применение современных измерительных приборов учета электрической энергии, совмещенных с устройством хранения и передачи данных. Применение измерительной техники позволяет построить автоматизированную систему сбора и дистанционной передачи данных от места учета до центра сбора и обработки данных. Система, построенная на базе интеллектуальных приборов учета различных источников и в зависимости от конечного назначения, носит название автоматизированной информационноизмерительной системы учета электроэнергии (АИИСУЭ). В свою очередь данные системы могут быть использованы либо для коммерческого учета (АСКУЭ), либо для технического (внутреннего) учета электрической энергии (АСТУЭ). Си- стемы коммерческого учета предназначены для измерения объема выработанной, переданной и потребленной электрической энергии электроустановками участников розничного и оптового рынка электроэнергетики.

Экономическая эффективность мероприятия по энергосбережению и повышению энергетической эффективности определяется системой стоимостных показателей, отражающих прибыльность (рентабельность) мероприятий по энергосбережению и повышению энергетической эффективности [3]. Основной «плюс» от внедрения системы АСКУЭ - это получение экономического эффекта в виде экономии средств на оплату потребленной электрической энергии, в частности, снижение затрат по оплате потерь.

Специалисты классифицируют потери электроэнергии на технические и коммерческие. Технические потери электроэнергии обусловлены физическими процессами, происходящими при передаче электроэнергии по электрическим сетям и выражающимися в преобразовании части электроэнергии в тепло в элементах сетей. Теоретически технические потери могут быть рассчитаны с определенной погрешностью, но и фактически измерить потери, например, в линии можно с определенными допусками погрешности. Это достигается с помощью приборов, имеющих погрешность $\pm 0,5 \%$, что может привести к результату от 1,5 до $2,5 \%$.

Коммерческие потери обусловлены хищениями электроэнергии, несоответствием оплаты электроэнергии бытовыми потребителями показаниям счетчиков и другими причинами, имеющими место в сфере потребления энергии. Коммерческие потери не имеют самостоятельного математического описания и, как следствие, не могут быть рассчитаны автономно. Их значение определяют как разницу между фактическими потерями и суммой трех вышеперечисленных составляющих [3].

Ознакомившись с научно-методической литературой по теме нашего исследования, в частности, касающейся определения экономического эффекта от внедрения АСКУЭ, нами не были обнаружены конкретные результаты апробации указанной методики. Авторы настоящей статьи предлагают рассмотреть порядок расчета экономического эффекта от внедрения АСКУЭ на примере сельского поселения, находящегося на территории Самарской области и состоящего из 320 домовладений. Данные по распределению и 
потреблению электрической энергии до и после применения АСКУЭ представлены в таблице 1.

Значительные потери обусловлены бесконтрольным потреблением электрической энергии населением. Потери в зимние месяцы наибольшие по объективным причинам: население использует электричество для обогрева (таблица 1). Потери электроэнергии обошлись обслуживающей организация ЖКХ в сумму 1632375 руб., которые она вынуждена была перечислить сбытовой организации.

Проектом внедрения системы АСКУЭ предполагалось сокращение потерь до 5\%. После реализации проекта фактические потери составили 3,18\% против 40,36\% до реализации проекта (таблица 1).

Прямые затраты на разработку и согласование проекта АСКУЭ, приобретение оборудования, модернизацию электрических сетей, установку и пуско-наладочные работы составили 6592144 руб. (стоимость определена на основании проектно-сметного расчета базисноиндексным методом). Реализация проекта проводилась поэтапно в течение одного календарного года (2019 г.). Показатели эффективности проекта представлены в таблице 2 .

При сравнении данных таблицы 1 очевидно, что объем поступления в сеть электроэнергии снизился с 741985 кВт в 2018 году до 704938 кВт в 2020 году. Одновременно с этим объем полезного объема потребленной электрической энергии увеличился на 54,4\%. Условно-годовая экономия составила 1550760 руб., что больше ожидаемого результата (таблица 2). Данная энергосберегающая технология - установка и запуск системы АСКУЭ на объектах ЖКХ является эффективным инструментом контроля над потреблением энергоресурсов.

Несмотря на очевидные положительные результаты, подтвержденные расчетами, внедрение системы АСКУЭ не нашла широкого применения. Существует ряд проблем, стоящих перед организациями ЖКХ, которые связаны с внедрением системы автоматизированного учета электроэнергии. Одна из проблем - получение средств на реализацию мероприятий по установке системы. Для получения необходимых денежных средств организация ЖКХ должна разработать и утвердить программу энергосбережения. Программа энергосбережения разрабатывается и утверждается в соответствии с требованиями Федерального закона от 23.11.2009 N 261-Ф3 [1] и Постановления Правительства РФ от 01.12. 2009 г. N 977 [2]. В Самарском регионе функции данных нормативных актов поделены между двумя ведомствами - Министерством энергетики и жилищно-коммунального хозяйства и Департаментом ценового и тарифного регулирования: первое проверяет целесообразность инвестиционной программы и утверждает его приказом, а второе либо включает затраты по данному инвестиционному проекту в тарифное регулирование, либо не включает. К тому же Департамент может самостоятельно растянуть

Таблица 1. Распределение электрической энергии в сельском поселении

\begin{tabular}{|l|c|c|c|}
\hline \multicolumn{1}{|c|}{ Показатели } & 2018 год & 2020 год & Изменение, \% \\
\hline Объем поступления электроэнергии в сеть, кВт·ч & 741985 & 705438 & 95,1 \\
\hline Объем потребленной электроэнергии, кВт·ч & 442481 & 683007 & 154,4 \\
\hline Потери электроэнергии: & & & 7,49 \\
- кВт·ч & 299504 & 22431 & \\
- в\% & 40,36 & 3,18 & \\
\hline
\end{tabular}

\section{Таблица 2. Показатели эффективности АСКУЭ}

\begin{tabular}{|l|r|}
\hline \multicolumn{1}{|c|}{ Наименование показателя } & 3начение \\
\hline Инвестиции в реализацию проекта АСКУЭ, руб. & 6592144 \\
\hline Срок реализации проекта АСКУЭ, кол-во лет & 1 \\
\hline Условно-годовая экономия, руб. & 1550760 \\
\hline Срок службы АСКУЭ, кол-во лет & 16 \\
\hline Срок окупаемости инвестиций, кол-во лет & 4,25 \\
\hline Чистый доход, руб. & 16669256 \\
\hline Индекс прибыльности & 2,53 \\
\hline
\end{tabular}


на более длительный срок инвестирование и, как следствие, увеличить срок ввода в эксплуатацию всей системы.

Как показывает практика, привлечение сторонних инвесторов к реализации подобных проектов, заключение энергосервисных контрактов не оправдано: отсутствие в тарифном регулировании процентов по содержанию привлеченных заемных средств инвесторов как необоснованных. Отметим также, что изыскав внутренние резервы и инвестировав их в систему автоматизированного коммерческого учета электрической энергии, организации ЖКХ не могут рассчитывать на дополнительную прибыль, так как средства, полученные сверх утвержденных Департаментом в текущем регулируемом периоде, будут изъяты в последующем периоде как излишне полученные.

Итак, с одной стороны, существуют современные технологии, использование которых гарантирует экономию энергоресурсов, с другой,- проблемы, связанные с внедрением этих технологий. В данном случае авторы видят выход в разработке регламента межфункционального взаимодействия между ведомствами, отвечающими за обеспечение реализации программ энергосбережения.

\section{Библиографический список}

1. Федеральный закон «Об энергосбережении и о повышении энергетической эффективности и о внесении изменений в отдельные законодательные акты Российской Федерации» от 23.11.2009 N 261-Ф3 (последняя редакция). 23 ноября 2009 года N 261-Ф3 - Consultant.ru>document/cons_doc_LAW_93978/ (Дата обращения: 16.05.2021).

2. Постановление Правительства РФ от 1 декабря 2009 г. N 977 «Об инвестиционных программах субъектов электроэнергетики» (с изменениями и дополнениями) - URL: https:/base.garant.ru

3. Бухмиров В.В., Нурахов Н.Н., Косарев П.Г., Фролов В.В., Пророкова М.В. Методические рекомендации по оценке эффективности энергосберегающих мероприятий - Томск: ИД ТГУ, 2014.-96 с.

4. Государственная программа Российской Федерации «Развитие энергетики» - URL: https://minenergo.gov. $\mathrm{ru} /$ node/323 - (Дата обращения: 18.04.2021).

5. Смертина П. На мегаватты накрутили мегацену, Газета «Коммерсантъ» № 21/П от 08.02.2021, стр. 1 - (Дата обращения: 18.04.2021).

6. Фазлиева, Я.С. Проблемы энергосбережения и энергоэффективности зданий в России / Я.С.Фазлиева, O.А. Ахмадеева. - Текст: непосредственный // Молодой ученый. - 2016. - № 7 (111) - C. 1020-1022.- URL: https://moluch.ru/archive/111/27864/ (Дата обращения: 26.04.2021).

7. Цветов Р.С. Энергосбережение и энергоэффективность: современный опыт России и зарубежных стран / Р.С.Цветов, В.Н. Мамяченков // XXI Международная конференция памяти профессора Л.Н. Когана «Культура, личность, общество в современном мире: методология, опыт эмпирического исследования», 22-23 марта 2018 г., Екатеринбург.- Екатеринбург: УрФУ, 2018.- С. 2241-2255 - (Дата обращения: 27.04.2021).

8. Статистический Ежегодник мировой энергетики 2020.- URL: https://yearbook.enerdata.ru/- (Дата обращения: 18.04.2021).

9. Новости ассоциации НП «Сообщество потребителей энергии» - URL: https://www.np-ace.ru/news/ partnership/- (Дата обращения: 18.04.2021).

10. Энергетическая стратегия России на период до 2035 года. - URL: https://minenergo.gov. ru/ - (Дата обращения: 16.05.2021). 